\title{
Study on the Stability of Slopes Reinforced by Composite Vegetation Combined with a Geogrid under Rainfall Conditions
}

\author{
Qizhi Hu (D), Yong Zhou, and Gaoliang Tao \\ College of Civil Construction and Environment, Hubei University of Technology, Wuhan 430068, China \\ Correspondence should be addressed to Qizhi Hu; 709317769@qq.com
}

Received 22 April 2021; Revised 26 June 2021; Accepted 7 August 2021; Published 19 August 2021

Academic Editor: Dezhong Kong

Copyright (C) 2021 Qizhi Hu et al. This is an open access article distributed under the Creative Commons Attribution License, which permits unrestricted use, distribution, and reproduction in any medium, provided the original work is properly cited.

\begin{abstract}
The planting of shrubs and trees on geogrid-reinforced slopes is an important ecological slope protection method that is frequently implemented in the rainy areas of southern China. First, this paper analyzes the soil-fixing principle of the geogrid and root system and demonstrates the feasibility of using composite vegetation of shrubs and trees to reinforce the slope with a geogrid. Using the Yushi Expressway project in Guizhou, we conducted a stability analysis of slopes under different working conditions and different reinforcement modes. We determined that the ecological protection method of combining composite vegetation with a geogrid can effectively increase the stability of slopes. The maximum displacement of the ecological slope under rainfall conditions was reduced by $82 \%$ compared with the original slope, and the overall stability was improved by $35 \%$. Four factors affect the slope stability: the depth of shrub reinforcement, depth of anchorage of trees, distribution of trees, and spacing of the geogrids. An orthogonal analysis considering these 4 factors with 3 levels was implemented. The following optimal combination was obtained to ensure ecological protection under rainfall conditions: a shrub reinforcement depth of $0.6 \mathrm{~m}$, a tree anchorage depth of $3 \mathrm{~m}$, a grid spacing of $0.4 \mathrm{~m}$, and a top-sparse and bottom-dense tree distribution. The combined slope protection schematic was applied to the Yushi Expressway project in Guizhou, and a strong reinforced slope protection effect was observed.
\end{abstract}

\section{Introduction}

Under rainfall conditions, the erosion resistance of exposed slopes decreases, and soil erosion increases, which can easily induce major natural disasters such as landslides $[1,2]$. Ecological slope protection efforts consider both engineering protection and environmental beautification and are widely used in China. Under the action of plant roots, the surface soil of an exposed slope is consolidated, and the shear strength is increased. The transpiration of plant leaves and suction of roots also improve the suction of the surface soil, stop ground runoff, and prevent scouring, which helps soil and water conservation. However, the contribution of root consolidation to slope stability is limited and not applicable to unstable or understable slopes. With the development of geosynthetics, geogrids have been widely used in slope engineering due to their obvious reinforcement effect and relatively economical nature [3]. Therefore, the planting of shrubs and trees on geogrid-reinforced slopes can improve the stability of slopes and highlight the ecological benefits of such conservation efforts since it is an important method for slope management in rainy areas.

At present, many scholars have conducted various studies on geogrids and root reinforced slopes. Among them, numerical simulation technology can intuitively analyze the failure mechanism inside the rock and soil and is widely used in slope stability analysis. For example, Sun et al. used the finite element software Midas-GTS to simulate the performance of reinforced soil slopes, and they compared the numerical simulation results with monitoring data to verify that numerical simulation techniques can reliably analyze geogridreinforced slopes $[4,5]$. Zhang et al. took the actual engineering of geogrid reinforcement of the slope as an example, analyzed the stability of the slope, and optimized the geogrid reinforcement scheme [6, 7]. Yang et al. discussed the mechanical mechanism of plant roots for soil consolidation and compared the stability of grass, shrub, arbor, and composite vegetation reinforcement under the slope. They noted that composite 
vegetation had significantly higher reinforcement effect than single vegetation [8]. Waldron et al. conducted a shear test on reinforced soil and noted that reinforced soil mainly exerted the reinforcement effect by improving the original cohesion of the soil [9-11]. Su et al. conducted a pull test of the root system of the arbor. The influence of the root diameter on the anchorage of arbor roots was quantitatively analyzed [12]. Abdi et al. calculated the spatial distribution of plant roots in the soil; they found that the roots of shrubs were mainly distributed $0.6 \mathrm{~m}$ below the slope, and the roots of trees could reach $3 \mathrm{~m}$ in length $[13,14]$. However, these studies did not consider the influence of geogrids and root systems on the hydraulic characteristics of slopes.

Rainfall infiltration is an important factor that induces slope instability $[15,16]$. Based on the theory of unsaturated seepage, Zhang et al. established a hydraulic-mechanical coupling numerical calculation model for reinforced soil slopes and studied the effects of rainfall infiltration on the stress, displacement, and pore pressure of geogrid-reinforced soil slopes $[17,18]$. Zhang et al. analyzed the seepage field distribution of root-fixed soil under rainfall conditions and found that when the root system continued to absorb water, the shear strength of unsaturated soil also increased $[19,20]$. $\mathrm{Ng}$ et al. studied the size and distribution of suction generated by plant roots in soil and noted that plants could significantly increase soil suction under both dry and rainy conditions [21]. Wang et al. conducted a slope model test under rainfall conditions and believed that plant roots could improve the hydraulic properties of the soil and reduce the impact of rainfall on the slope runoff [22-24]. Song et al. proposed a composite soil treatment and slope protection method using the geocell structures and the wheat straw reinforcement, which can effectively reduce soil erosion on the slope [25].

These studies mainly focused on the influence of a single reinforcement mode and a single factor on the slope deformation and stability. There are few studies on slope reinforcement by composite vegetation with geogrids. With the improvement of the dual requirements of economic and ecological benefits, joint ecological slope protection technology has widely become the optimal choice for slope treatment. However, its work performance is more complicated, and there are many influencing factors. There is no clear understanding of the design plan for planting shrubs and trees on slopes reinforced by geogrids. Especially under rainfall conditions, it is of great significance to quantify the influence of various factors on the mechanical and hydraulic characteristics of ecological slopes. Therefore, to popularize this technology in engineering, it is necessary to study the stability of composite vegetation with geogrid reinforcement under rainfall conditions.

\section{Soil Fixation Mechanism of Geogrid and Root Systems}

As common reinforcement materials, geogrid and root systems can affect the mechanical properties of the soil and root system as an active medium. They can absorb water from different soil depths through the transpiration of plant leaves, increase the soil suction, and change the hydraulic characteristics of unsaturated soil. We analyzed the soil fixation mechanism of a geogrid and a root system based on mechanical and hydraulic soil properties as follows.

2.1. Mechanical Activation Behavior. Geogrids and root systems have high tensile strengths. After being implanted in the soil, roots can interact with the soil to improve its tensile and shear strength and form a reinforced soil. Therefore, its mechanical properties can be quantitatively analyzed by reinforced soil theory, which mainly includes two types: the friction reinforcement principle and quasi-cohesive force mechanism.

The principle of friction reinforcement is that the reinforcing material is firmly fixed inside the soil body under the action of soil pressure; when the relative displacement of the soil body and reinforcing material occurs, the slip force will be transferred to the reinforcing material. Due to the friction between soil and tendons and the high tensile strength of the tendons, the soil deformation can be limited, which improves the soil stability. Section $d_{l}$ of the reinforced soil is selected for analysis, as shown in Figure 1:

$$
\begin{aligned}
F & =2 \sigma_{n} f b d_{l}, \\
d_{T} & =T_{1}-T_{2},
\end{aligned}
$$

where $F$ is the frictional resistance, $\sigma_{n}$ is the effective stress that acts on the reinforced material, $f$ is the friction coefficient, $b$ and $d_{l}$ are the width and length of the reinforced material, and $d_{T}$ is the tensile force on the reinforced material. When $F>d_{T}$, the reinforced soil is in a stable state, and vice versa for destabilization.

The mechanism behind quasi-cohesion is to regard the reinforced soil as a composite material. Reinforcements play a similar role in the confining pressure, which limits the soil deformation. Reinforced soil mainly exerts the reinforcement effect by improving the original cohesion of the soil. As shown in Figure 2, the strength envelope of reinforced soil is parallel to that of unreinforced soil, and only the point of intersection with the vertical axis is significantly different. When the confining pressure $\sigma_{3}$ is constant and the soil reaches the ultimate equilibrium state, the maximum principal stress $\sigma_{1}^{\prime}$ of the reinforced soil is obviously greater than the maximum principal stress $\sigma_{1}$ of unreinforced soil, and the strength of the reinforced soil is substantially improved. When the maximum principal force $\sigma_{1}^{\prime}$ is constant, the minimum principal stress $\sigma_{3}^{\prime}$ of unreinforced soil can be calculated using its strength envelope. Figure 2 shows that $\sigma_{3}^{\prime}$ is significantly larger than $\sigma_{3}$, which indicates that the tendons can limit the soil deformation and increase the enclosing pressure. The increase in confining pressure is defined as follows:

$$
\begin{aligned}
\Delta \sigma_{3} & =\sigma_{3}^{\prime}-\sigma_{3}=2 \Delta c \cdot \tan \left(45^{\circ}-\frac{\varphi}{2}\right) \\
\Delta \sigma_{3} & =\left(\sigma_{1}^{\prime}-\sigma_{1}\right) \tan ^{2}\left(45^{\circ}-\frac{\varphi}{2}\right) \\
& =\Delta \sigma_{1} \cdot \tan ^{2}\left(45^{\circ}-\frac{\varphi}{2}\right)
\end{aligned}
$$




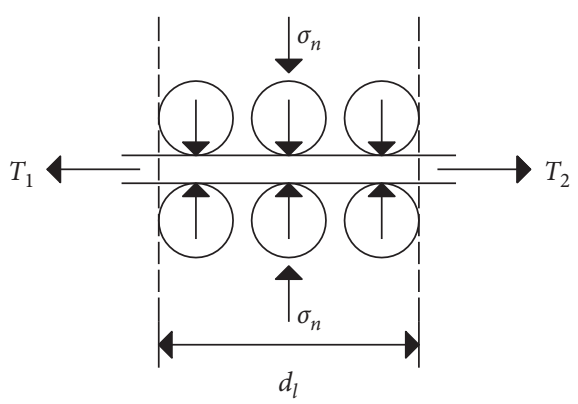

Figure 1: Principle of friction reinforcement.

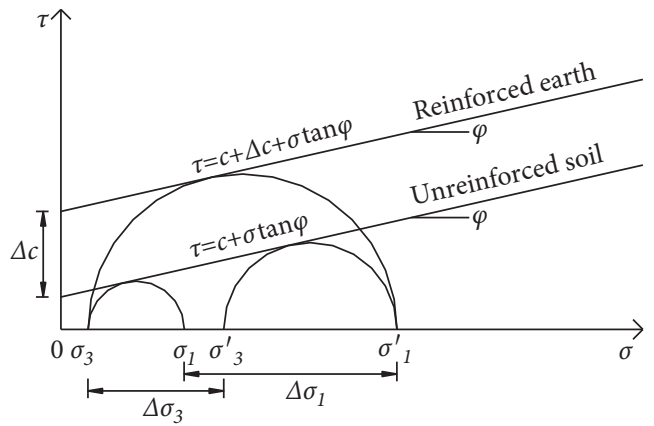

Figure 2: Diagram of the strength analysis of reinforced soil.

From formulas (2) and (3), we obtain

$$
\Delta c=\frac{1}{2} \Delta \sigma_{1} \cdot \tan \left(45^{\circ}-\frac{\varphi}{2}\right),
$$

where $\Delta c$ is the quasi-cohesive force, $\varphi$ is the friction angle in the soil body, and $\Delta \sigma_{1}$ is the maximum principal stress difference.

2.2. Hydraulic Performance. Unlike other reinforced materials, the root system, as a type of active reinforcement, can play the mechanical role of reinforcement and anchoring, absorb water from different soil depths through the transpiration of plant leaves, reduce the pore water pressure of the soil, improve soil suction, and change the permeability characteristics of unsaturated soil. Therefore, the influence of the root system on soil hydraulic characteristics can be quantitatively analyzed using the unsaturated permeability theory, which is mainly reflected in two aspects.

On one hand, based on unsaturated theory, a shear strength formula considering matrix suction is established [26]:

$$
\tau=c+\left(\sigma-\mu_{a}\right) \tan \varphi+\left(\mu_{a}-\mu_{w}\right) \tan \left[(\tan \varphi) \frac{\theta-\theta_{r}}{\theta_{s}-\theta_{r}}\right],
$$

where $\tau, \sigma, c$, and $\varphi$ are the shear stress, principal stress, cohesion, and internal friction angle of the soil in sequence, respectively, $\mu_{a}-\mu_{w}$ is the matrix suction, $\mu_{a}$ is the pore-air pressure, $\mu_{w}$ is the pore water pressure, $\theta$ is the volumetric water content, $\theta_{s}$ is the saturated water content, and $\theta_{r}$ is the residual water content. This formula shows that plant roots can increase soil suction, reduce the pore water pressure, and consequently increase the shear strength of the soil.

On the other hand, the relationship between suction and permeability coefficient of unsaturated soil can be described as follows:

$$
K(s)=K_{s} \frac{\int_{\text {Ins }}^{b}\left(\left(\theta\left(e^{y}\right)-e(s)\right) / e^{y}\right) \theta^{\prime}\left(e^{y}\right) \mathrm{d}_{y}}{\int_{\operatorname{Ins}_{\mathrm{ave}}}^{b}\left(\left(\theta\left(e^{y}\right)-\theta_{s}\right) / e^{y}\right) \theta^{\prime}\left(e^{y}\right) \mathrm{d}_{y}},
$$

where $K_{s}$ is the saturated permeability coefficient, $s=\mu_{a}-\mu_{w}, b=\ln \left(10^{6}\right), y$ is the dummy variable of the suction integral, and $\theta^{\prime}$ is the derivative of $\theta$. From this formula, the soil suction is negatively related to the permeability coefficient. The change curve of various soil permeability coefficients with suction in Figure 3 shows that the permeability coefficient of soil decreases with increasing suction. Therefore, the ecological slope can increase the soil suction and reduce the permeability coefficient under the action of root suction. During rainfall, it can reduce the infiltration of rainwater and reduce the risk of soil erosion.

After the above analysis, as reinforced materials, the geogrid and root system play the role of reinforced anchors in terms of their mechanical properties, and the principle of soil fixation is identical. In actual engineering practices, due to the diversity of the plant root distribution, the root system can be intertwined with the grid through the grid gap to form a joint entity, which can limit the relative displacement of the geogrid and soil and prevent the root system from being pulled out to improve the shear strength of the soil. Simultaneously, the suction effect of the root system can 


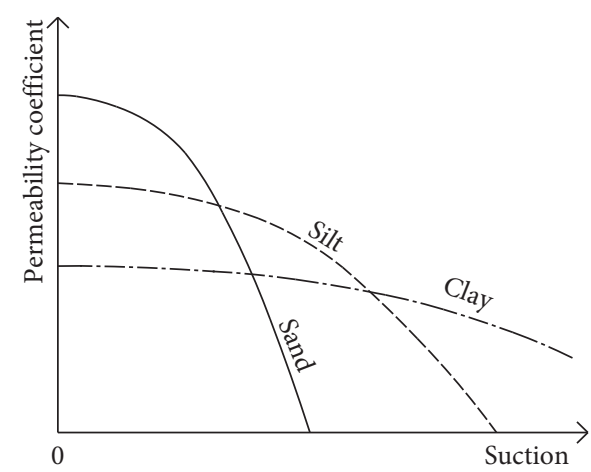

FIgURE 3: Diagram of the change in soil permeability coefficient with suction.

improve the hydraulic properties of the soil, increase the shear strength of the soil, reduce the infiltration coefficient, and reduce the harm of rainwater to the soil. In summary, the ecological slope protection method of composite vegetation with geogrids can fully utilize the reinforcing and anchoring effects of root systems and geogrids, effectively reduce the risk of soil erosion, and provide a theoretical basis for promotion.

\section{Numerical Simulation of Combined Ecological Slope Protection}

3.1. Engineering Background. The 10th section of the Guizhou Yushi Expressway starts from Majiao, Tianxing Township, Cengong County and ends at the Yangtang River, Tianxing Township, Cengong County, with a total length of $8.155 \mathrm{~km}$. There are many deep excavation and high filling subgrades along the entire line of the tender section, with 3.47 million square meters of excavation and 3.06 million square meters of filling and rainfall conditions throughout the year. Therefore, the main technical difficulties in the construction process are abundant rainfall, difficulties associated with soil and water conservation, and more highside and larger slopes. In addition, an urgent blockade of this project is how to adapt to local conditions in the context of green transportation, ensure the safety, stability, and green premise of the integration, optimize various protection methods, and achieve maximum economic and ecological benefits.

3.2. Establishment of the Numerical Model and Validation. MIDAS/GTS provides a slope stability analysis under various working conditions, which is widely used in slope stability calculations, and the calculation accuracy has been verified. Therefore, the finite element software Midas-GTS is used to simulate the joint ecological slope protection. A section of the slope of the Yushi Expressway in Guizhou was selected for analysis, which has a slope fill height of $6 \mathrm{~m}$ and a slope of $45^{\circ}$. To achieve maximum economic and ecological benefits, ecological protection of the composite vegetation with geogrids is performed on the slopes. The composite vegetation consists of a combination of shrubs and trees. Shrub roots are mainly distributed within $0.6 \mathrm{~m}$ below the slope surface. To facilitate the simulation, the arbor root system is simplified. The main roots of the arbor are vertically distributed with a length of $3 \mathrm{~m}$ and a diameter of $0.1 \mathrm{~m}$. The lateral roots are distributed symmetrically about the main root, parallel to the slope, with a length of $0.6 \mathrm{~m}$, a diameter of $0.02 \mathrm{~m}$, and a horizontal planting interval of $2 \mathrm{~m}$. The geogrid is $6 \mathrm{~m}$ long. The layout spacing is $0.6 \mathrm{~m}$. To reduce the influence of the size effect, the grid of the slope model is extended and converted according to the research of Zheng et al. on the calculation accuracy of numerical simulation [27]. The specific slope form and model dimensions are shown in Figure 4.

Due to the well-developed root system of shrubs with diverse and dense distribution patterns, they can interlock with the soil and form a joint mass. Therefore, the soil in the shrub reinforcement area is simulated in the form of a root soil complex. The Mohr-Coulomb model is used for plain soil and reinforced soil. Both geogrid and arbor root system were simulated using a separated elastic model. A normal constraint was applied around the model with a fixed constraint at the bottom and a rainfall boundary with an intensity of $5 \mathrm{~mm} / \mathrm{h}$ at the top for $24 \mathrm{~h}$, which was recorded every $6 \mathrm{~h}$. The initial water level was $4.5 \mathrm{~m}$. According to the engineering geological survey report and corresponding references, the mechanical parameters and hydraulic characteristic parameters of plain soil and reinforced soil are provided. Among them, the mechanical parameters of both geogrid and arboreal root system were obtained from indoor tensile tests, which are shown in Tables 1 and 2 .

To verify the accuracy of the built numerical model, further research was performed on the joint ecological slope. The strength reduction method and stress limit equilibrium method are used to calculate the stability of the original slope. The safety factor of the slope obtained by the strength reduction method is 1.890 , which is closer to the safety factor of 1.906 calculated by the stress limit equilibrium method. Thus, the numerical model can be used for the stability calculation of combined ecological slope protection.

3.3. Result Analysis. Figure 5 shows the displacement field of the original slope and ecological slope under the combined reinforcement after $24 \mathrm{~h}$ of rainfall. As seen from the figure, the slope displacement field considerably changes under combined ecological protection. First, in terms of displacement values, the maximum displacements of the 


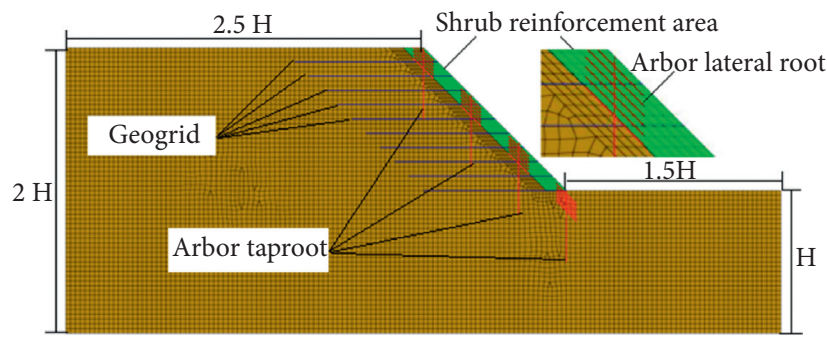

FIgURE 4: Slope model.

TABLE 1: Mechanical parameters of the materials.

\begin{tabular}{lccccc}
\hline Material & Volumetric weight $r\left(\mathrm{kN} / \mathrm{m}^{3}\right)$ & Cohesion $c(\mathrm{kPa})$ & Friction angle $\varphi\left(^{\circ}\right)$ & Elastic modulus $E(\mathrm{MPa})$ & Poisson's ratio $\mu$ \\
\hline Plain soil & 18 & 10.3 & 22.85 & 4 & 0.3 \\
Shrub reinforced soil & 18 & 24.6 & 28.39 & 4.8 & 0.3 \\
Arbor lateral roots & 12.85 & - & - & - & 1500 \\
Geogrid & - & - & - & 0.3 & 0.23 \\
\hline
\end{tabular}

TABle 2: Hydraulic characteristic parameters of the soil.

\begin{tabular}{lccccc}
\hline Material & Fitting parameter $a\left(\mathrm{kPa}^{-1}\right)$ & Fitting parameter $n$ & $\theta_{r}\left(\mathrm{~m}^{3} / \mathrm{m}^{3}\right)$ & $\theta_{s}\left(\mathrm{~m}^{3} / \mathrm{m}^{3}\right)$ & $k_{s}\left(10^{-6} \mathrm{~m} / \mathrm{s}\right)$ \\
\hline Plain soil & 0.114 & 1.806 & 0.017 & 0.45 & 3.29 \\
Shrub reinforced soil & 0.176 & 1.798 & 0.018 & 0.456 & 3.18 \\
\hline
\end{tabular}

original slope and ecological slope are $186.5 \mathrm{~mm}$ and $33.4 \mathrm{~mm}$, respectively, i.e., the slope displacement is reduced by $82 \%$. Second, the maximum displacement of the original slope is located at the foot of the slope, the stress is relatively concentrated, and the slope exhibits an overall slippage effect. Meanwhile, the sensitive area of the maximum displacement of the ecological slope has changed and is located in the middle and upper parts of the slope. The reason is that, under the action of rainfall, the weight of the soil sharply rises; the soil at the foot of the slope is most severely eroded by rainwater, and the original slope has an integral sliding from top to bottom. However, under the combined action of the geogrid and root system of the ecological slope, the displacement at the toe of the slope is fully restricted. Simultaneously, the suction effect of the root system reduces the pore water pressure at the foot of the slope and improves the shear strength of the soil at the foot of the slope. However, the effective stress on the tendons in the middle and upper parts of the slope is relatively small, the tendon reinforcement effect is limited, and the connection force between shrub reinforcement area and plain soil is insufficient, which can easily produce relative slip and cause shallow damage to the slope.

According to research on the mechanism of root soil fixation, considering the influence of the root system on the hydraulic characteristics of the slope, the unsaturated strength reduction method is used to calculate the slope stability under different reinforcement modes. As shown in Figure 6, under natural working conditions, the shrub reinforcement has limited effect on the slope, but the tree and geogrid reinforcement has an obvious effect. Compared with the original slope, the slope safety factor increases by $6 \%$ and $9 \%$, respectively. In the combined form, the ecological protection method of composite vegetation with the geogrid has the highest safety factor, which is represented by an increase of $12 \%$ relative to the reinforcement effect of a single vegetation with geogrid. Under rainfall conditions, as rainfall continued, the effect of the shrub reinforcement considerably improved, and the slope safety factor increased by $6 \%$ after $24 \mathrm{~h}$ of rainfall. Although the shrub reinforcement has limited contribution to the slope stability, it can effectively reduce the hazard of rainfall on the slope. Among them, the ecological protection method of composite vegetation with a geogrid still obtains the highest safety factor, which is $35 \%$ higher than that of the original slope.

Regardless of whether rainfall occurs, composite vegetation with the geogrid reinforcement mode has the best performance. Under the anchoring action of the geogrid and arbor root system, the reinforced soil in the shrub reinforcement area can be connected with the stabilizing layer, which improves the stability of the shallow soil. Simultaneously, the root system passes through the grid gap and interweaves with the grid to form a united entity. This unity effectively plays the role of geogrid, root reinforcement, and anchor, limits slope deformation, and changes the sensitive area of maximum ecological slope displacement. It can improve the stability of the slope under natural working conditions and greatly reduce the hazard of rainfall to the slope.

\section{Optimization of the Combined Ecological Slope Protection}

At present, most studies on the effect of ecological slope reinforcement are single-factor analyzes, while the ecological protection method of composite vegetation with geogrids 


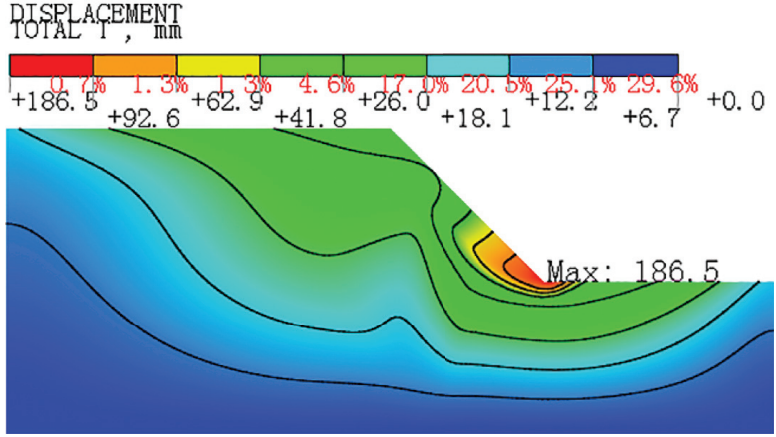

(a)

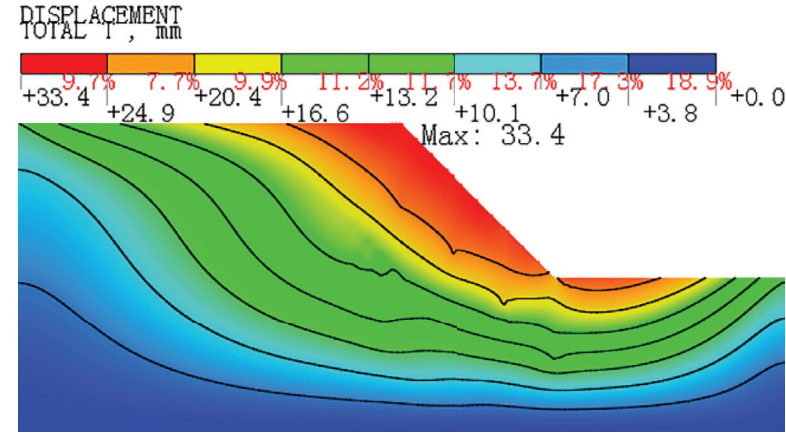

(b)

FiguRE 5: Displacement field of the original slope and ecological slope after $24 \mathrm{~h}$ of rainfall. (a) Original slope. (b) Ecological slope protection by composite vegetation with geogrid reinforcement.

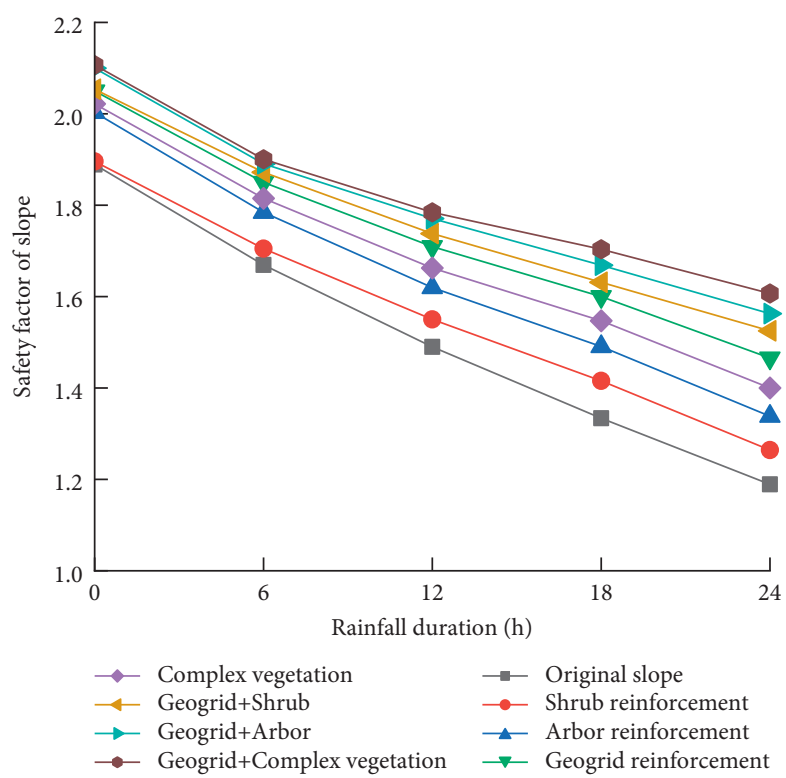

FiguRE 6: Slope stability under various protection methods.

has multiple factors and multiple levels, which affect one another. Therefore, compared with the single-factor analysis, the orthogonal model test can quantitatively calculate the degree of influence of each factor on the stability of ecological slopes under different working conditions. This process can also obtain the optimal combination form to guide the application of joint ecological slope protection technology in practical engineering.

4.1. Establishment of the Orthogonal Model. Based on the existing research, taking the shrub reinforcement depth, arbor anchoring depth, arbor distribution form, and geogrid spacing as influencing factors, we designed an orthogonal model test with 4 factors and 3 levels, as shown in Table 3. The distribution forms of trees include uniform (a), upper dense and lower sparse (b), and upper sparse and lower dense (c) distributions. Specific planting methods are shown in Figure 7.
4.2. Orthogonal Test Results. Nine combinations of 4 factors and 3 levels under different working conditions were numerically calculated, and the results are shown in Table 4. The calculation results are analyzed in the range in Table 5. A larger extreme difference indicates that this factor has a greater influence on the slope stability, which can be used to obtain the degree of influence of different factors on the ecological slope stability under different working conditions and derive the optimal combination form, which is reported in Table 5.

Under natural working conditions, trees have the largest extreme difference in anchorage depth, and shrubs have the smallest extreme difference in reinforcement depth. Therefore, the degree of influence of each factor on the stability of ecological slopes is as follows: depth of anchorage of trees $>$ spacing of geogrid $>$ form of distribution of trees $>$ depth of reinforcement of shrubs. Meanwhile, it can be seen from Figure $8(\mathrm{a})$, the slope safety coefficient first increases and subsequently decreases with increasing 
TABLE 3: Orthogonal design level of optimized parameters (unit: $\mathrm{m}$ ).

\begin{tabular}{lcccc}
\hline \multirow{2}{*}{ Level } & \multicolumn{3}{c}{ Optimization parameters } & \\
& Shrub reinforcement depth & Arbor anchoring depth & Arbor distribution form & Geogrid spacing \\
\hline 1 & 0.2 & 1 & $\mathrm{a}$ & 0.4 \\
2 & 0.4 & 2 & $\mathrm{~b}$ & 0.6 \\
3 & 0.6 & 3 & $\mathrm{c}$ & 0.8 \\
\hline
\end{tabular}

reinforcement depths; the slope safety increases with increasing arbor anchorage depths; the slope safety first increases and then stabilizes with the decrease of the geogrid spacing. The size of the slope safety coefficient under different forms of arbor distribution follows the following order: upper sparse and lower dense $>$ uniform distribution $>$ upper dense and lower sparse. The above result shows that the stability of shallow slopes can be improved with increasing reinforcement depth. However, when the influence depth of reinforced soil is too large, the intermediate connection force is insufficient, which increases the risk of sliding along shallow slopes and induces shallow slope instability. Increasing the anchoring depth and reducing the spacing of the geogrid can improve the reinforced anchoring effect of the reinforced material. However, when the spacing of the grids is reduced, the reinforcement effect will not improve. Considering the economic benefits of the project, the spacing of grating should be $0.6 \mathrm{~m}$. In addition, the sensitive area of the slope safety factor is at the foot of the slope, and the arbor adopts the upper sparse and lower dense distribution, which can effectively play the role of anchoring. In summary, under natural working conditions, the optimal combination form is as follows: the reinforcement depth is $0.4 \mathrm{~m}$, the anchorage depth is $3 \mathrm{~m}$, the arbor is sparse on the top and dense at the bottom, and the grid spacing is $0.6 \mathrm{~m}$.

Under rainfall conditions, the degree of influence of each factor on the stability of ecological slopes is as follows: depth of anchorage of trees $>$ depth of reinforcement of shrubs $>$ spacing of geogrid $>$ form of distribution of trees. The extreme difference in shrub reinforcement depth was greatly enhanced. Thus, the effect of shrub reinforcement on the hydraulic properties of the slope was considerably greater than its mechanical properties. Under joint ecological protection, shrub reinforcement can effectively reduce the hazard of rainfall on the slope stability and improve the hydraulic characteristics of the slope. It can be seen from Figure $8(\mathrm{~b})$ that slope safety factor, shrub reinforcement depth, arbor anchorage depth, and geogrid spacing are linearly related, which obviously differs from the trend of natural working conditions. A greater depth of shrub reinforcement corresponds to a greater degree of improvement in the hydraulic properties of the slope and better protection against rainfall hazards. In other words, when planting shrubs in rainfall areas, vegetation with more developed root systems should be used. Simultaneously, rainfall increases the tendency of relative displacement between the soil and the grid. This reinforcement effect can be effectively improved by reducing the grid spacing, so the grid spacing should be $0.4 \mathrm{~m}$. Under different arbor distribution forms, the slope safety factor follows the following order: upper sparse and lower dense > upper dense and lower sparse > evenly distributed. The optimal reinforcement effect can be obtained with the upper sparse and lower dense planting method. The root system in the lower part more easily passes through the plastic zone of the slope and gives full play to the anchoring effect of the root system. However, under the action of rainfall, the displacementsensitive area of the ecological slope is changed, and the maximum displacement is located in the middle and upper parts of the slope. Therefore, unlike the natural working condition, the planting method of upper density and lower sparsity can improve the connection force between the shallow soil and the stable layer in the middle and upper parts of the slope, prevents shallow damage to the slope, and is better than the uniform distribution. In summary, under rainfall conditions, the optimal combination form is as follows: reinforcement depth of $0.6 \mathrm{~m}$, anchorage depth of $3 \mathrm{~m}$, sparse arbor at the top, dense arbor at the bottom, and grid spacing of $0.4 \mathrm{~m}$.

The above analysis shows that, under natural and rainfall conditions, the degree of influence of various factors on the stability of ecological slopes is very different, and the obtained optimal combination form is also different. Therefore, for the combination forms of ecological slopes in different regions, the corresponding optimal combination forms should be formulated according to the local hydrogeological conditions.

4.3. Practical Engineering Application. We applied the optimal combination form obtained from the orthogonal model test to the corresponding actual project to verify the superiority of the combination.

According to research on the reinforcement mode of composite vegetation with geogrids, the combined ecological protection method can be applied to the side slope project of the Yushi Expressway in Guizhou. Therefore, a geogrid was laid on the filling section of a subgrade side slope, and a vegetation composite consisting of shrubs and trees was planted on the slope. The grid spacing was $0.4 \mathrm{~m}$, and trees were planted with sparse tops and dense bottoms. Figure 9 shows a site picture of ecological protection in the bid section. By monitoring the finished slope project, we found that, in the early stage of planting, the reinforcement of the geogrid improved the slope stability. As the vegetation growth period progressed, the root system passed through the mesh of the geogrid. The vegetation and geogrid were interweaved and jointly reinforced and anchored. Hence, the reinforcement of composite vegetation and ecological benefits considerably improved. Under rainfall conditions, shrubs could effectively weaken splash erosion and reduce the scouring of slopes by rainwater. No obvious soil erosion 


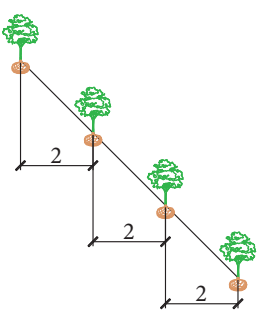

(a)

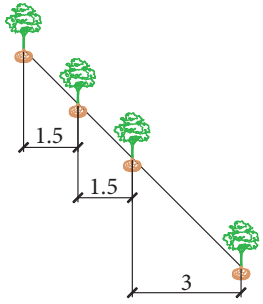

(b)

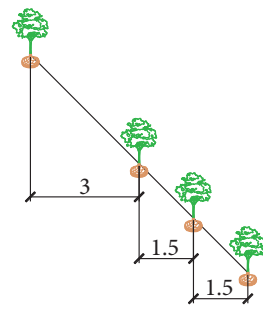

(c)

FIGURE 7: Schematic diagram of the tree planting pattern (unit: $\mathrm{m}$ ).

TABLE 4: Orthogonal test results of the slope safety factor.

\begin{tabular}{|c|c|c|c|c|c|c|}
\hline \multirow[b]{2}{*}{ Combining forms } & \multicolumn{4}{|c|}{ Optimization parameters } & \multicolumn{2}{|c|}{ Safety factor of slope } \\
\hline & Shrub reinforcement depth & Arbor anchoring depth & Arbor distribution form & $\begin{array}{l}\text { Geogrid } \\
\text { spacing }\end{array}$ & Rainfall $0 \mathrm{~h}$ & Rainfall $24 \mathrm{~h}$ \\
\hline 1 & 0.2 & 1 & $\mathrm{a}$ & 0.4 & 2.075 & 1.522 \\
\hline 2 & 0.2 & 2 & $\mathrm{~b}$ & 0.6 & 2.094 & 1.529 \\
\hline 3 & 0.2 & 3 & c & 0.8 & 2.100 & 1.563 \\
\hline 4 & 0.4 & 1 & $\mathrm{~b}$ & 0.8 & 2.063 & 1.538 \\
\hline 5 & 0.4 & 2 & c & 0.4 & 2.101 & 1.556 \\
\hline 6 & 0.4 & 3 & $\mathrm{a}$ & 0.6 & 2.109 & 1.581 \\
\hline 7 & 0.6 & 1 & c & 0.6 & 2.078 & 1.563 \\
\hline 8 & 0.6 & 2 & $\mathrm{a}$ & 0.8 & 2.088 & 1.566 \\
\hline 9 & 0.6 & 3 & $\mathrm{~b}$ & 0.4 & 2.105 & 1.613 \\
\hline
\end{tabular}

TABLE 5: Range analysis of the slope safety factor.

\begin{tabular}{lccccc}
\hline Rainfall duration $(\mathrm{h})$ & Average water & Shrub reinforcement depth & Arbor anchoring depth & Arbor distribution form & Geogrid spacing \\
\hline \multirow{4}{*}{0} & K1 & 2.090 & 2.072 & 2.091 & 2.087 \\
& K2 & 2.091 & 2.094 & 2.093 & 2.094 \\
& K3 & 2.090 & 2.105 & 0.006 & 2.084 \\
& Range & 0.001 & 0.033 & 1.556 & 0.010 \\
\hline \multirow{4}{*}{24} & K1 & 1.538 & 1.541 & 1.560 & 1.564 \\
& K2 & 1.558 & 1.550 & 1.561 & 1.558 \\
& K3 & 1.581 & 0.045 & 0.005 & 0.008 \\
\hline
\end{tabular}

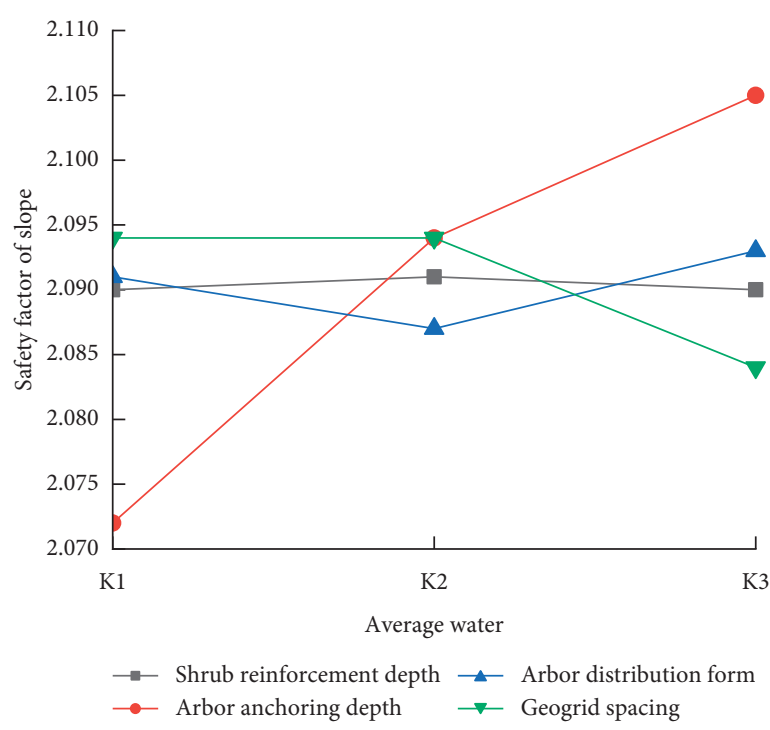

(a)

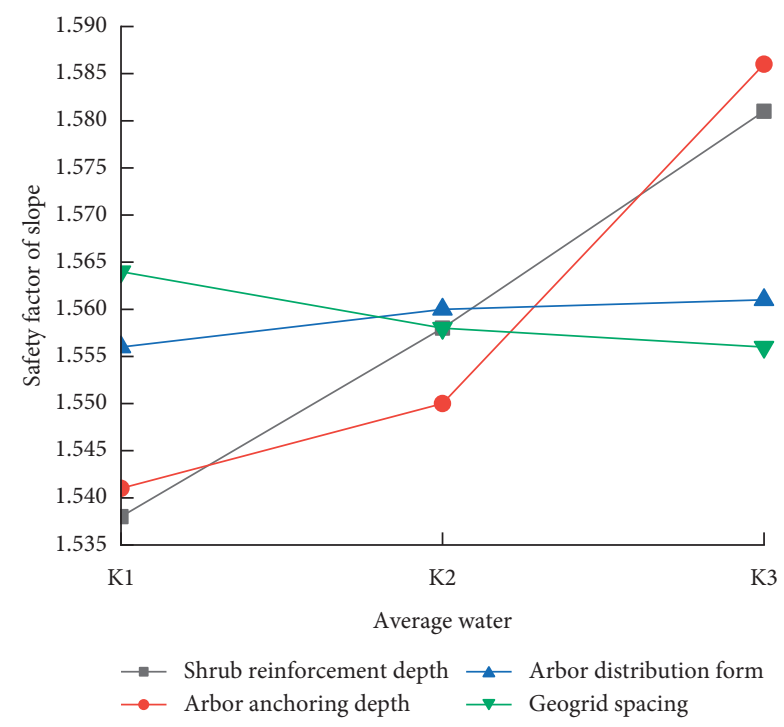

(b)

FIGURE 8: Curves of slope safety factor varying with the average level of various factors under different working conditions. (a) Rainfall $0 \mathrm{~h}$. (b) Rainfall $24 \mathrm{~h}$. 


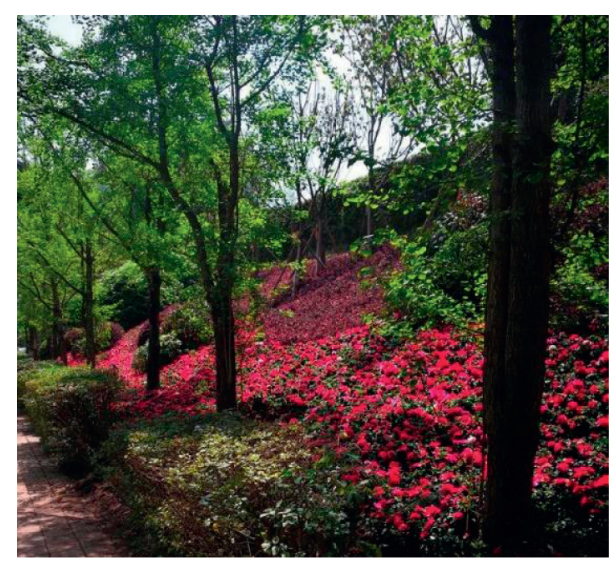

FIgURE 9: Practical application of joint ecological protection.

occurred, and the local ecological environment was quickly restored, which achieved good reinforcement and demonstrates the ecological benefits of the project.

\section{Conclusions}

For the ecological slope protection technology of composite vegetation with a geogrid, theoretical analysis, numerical simulation, optimization design, and practical application were performed. The mechanical and hydraulic characteristics of the combined ecological slope were comprehensively evaluated. The impacts of the shrub shallow root reinforcement, arbor deep root anchoring, and combined geogrid reinforcement on the stability of the slope were quantified. The design of the combined ecological slope was optimized. All of this work will contribute to the design and application of ecological slope engineering. The study indicates that

(1) Based on the reinforced soil theory and unsaturated seepage theory, we demonstrated the feasibility of using composite vegetation of shrubs and trees to reinforce the slope with a geogrid.

(2) The ecological protection method of composite vegetation with geogrids is obviously better than the single reinforcement method. The maximum displacement of the ecological slope under rainfall conditions decreased by $82 \%$ compared to the original slope, and the overall stability increased by $35 \%$.

(3) The shrub reinforcement has a much greater effect on the hydraulic characteristics of the slope than its mechanical characteristics. The anchoring depth of the arbor root system plays a key role in ensuring slope stability. The encryption of geogrid spacing can reduce the hazard of rainfall to the slope. According to the degree of influence of various factors on the stability of ecological slopes, the optimal combination form under different working conditions is obtained. The optimal combination form is applied to the actual project, and good reinforcement and ecological benefits have been achieved.
(4) Due to the diversity of root distribution morphology, this study simplified the arbor root system, which can only reflect the spatial relationship between the root system and the geogrid. Therefore, future research will examine how to more truly reflect the actual effect of the joint reinforcement of the root system and grid.

\section{Data Availability}

The data used to support the findings of this study are available from the corresponding author upon request.

\section{Conflicts of Interest}

The authors declare that they have no conflicts of interest.

\section{Acknowledgments}

This research was supported by the General Project of the National Natural Science Foundation of China (51978249).

\section{References}

[1] L. J. Guo, R. M. Liu, C. Men et al., "Multiscale spatiotemporal characteristics of landscape patterns, hotspots, and influencing factors for soil erosion," Science of the Total Environment, vol. 779, Article ID 146474, 2021.

[2] B. Y. Guo, Y. Q. Niu, V. S. Mantravad, L. Zhang, and G. Z. Liu, "The variation of rainfall runoff after vegetation restoration in upper reaches of the Yellow river by the remote sensing technology," Environmental Science and Pollution Research, vol. 2, 2021.

[3] Y.-J. Kim, A. R. Kotwal, B.-Y. Cho, J. Wilde, and B. H. You, "Geosynthetic reinforced steep slopes: current technology in the United States," Applied Sciences, vol. 9, no. 10, Article ID 9102008, 2019.

[4] Y. Sun, H. Xu, P. Gu, and W. Hu, "Application of FBG sensing technology in stability analysis of geogrid-reinforced slope," Sensors (Basel, Switzerland), vol. 17, no. 3, p. 597, 2017.

[5] M. B. Guo, L. Song, J. Liu, and Y. F. Duan, "Analysis of mechanical behavior of geogrid-reinforcecd steep embankment," Journal of Shihezi University (Natural Science), vol. 37, no. 6, pp. 708-713, 2019, in Chinese.

[6] R. Zhang, M.-x. Long, T. Lan, J.-l. Zheng, and C. Geoff, "Stability analysis method of geogrid reinforced expansive soil slopes and its engineering application," Journal of Central South University, vol. 27, no. 7, pp. 1965-1980, 2020.

[7] L. S. Shen, G. Q. Yang, H. T. Cheng, R. J. Zheng, and J. C. Chen, "Optimization technology for geogrid-reinforced subgrade widening projects of highways," Chinese Journal of Geotechnical Engineering, vol. 35, no. 74, pp. 789-793, 2013, in Chinese.

[8] W. H. Yang, D. W. Zhang, Q. Yan, and Z. L. Mao, "Numerical analysis on stability of slope reinforced by combination of deep and shallow roots," Journal of Southeast University (Natural Science Edition), vol. 50, no. 1, pp. 161-168, 2020, in Chinese.

[9] L. J. Waldron, "The shear resistance of root-permeated homogeneous and stratified soil," Soil Science Society of America Journal, vol. 41, no. 5, pp. 843-849, 1977. 
[10] D. H. Gray and T. Al-Refeai, "Behavior of fabric-versus fiberreinforced sand," Journal of Geotechnical Engineering, vol. 112, no. 8, pp. 804-820, 1986.

[11] C. F. Chen, H. X. Liu, and Y. P. Li, "Study on grassrootsreinforced soil by laboratory triaxial test," Rock and Soil Mechanics, vol. 28, pp. 2041-2045, 2007, in Chinese.

[12] L.-j. Su, B.-l. Hu, Q.-j. Xie, F.-w. Yu, and C.-l. Zhang, "Experimental and theoretical study of mechanical properties of root-soil interface for slope protection," Journal of Mountain Science, vol. 17, no. 11, pp. 2784-2795, 2020.

[13] E. Abdi, B. Majnounian, M. Genet, and H. Rahimi, "Quantifying the effects of root reinforcement of Persian ironwood (Parrotia persica) on slope stability; a case study: hillslope of Hyrcanian forests, northern Iran," Ecological Engineering, vol. 36 , no. 10, pp. 1409-1416, 2010.

[14] J. J. Roering, K. M. Schmidt, J. D. Stock, W. E. Dietrich, and D. R. Montgomery, "Shallow landsliding, root reinforcement, and the spatial distribution of trees in the Oregon coast range," Canadian Geotechnical Journal, vol. 40, no. 2, pp. 237-253, 2003.

[15] L. Zeng, H.-b. Bian, Z.-n. Shi, and Z.-m. He, "Forming condition of transient saturated zone and its distribution in residual slope under rainfall conditions," Journal of Central South University, vol. 24, no. 8, pp. 1866-1880, 2017.

[16] K.-H. Yang, J. N. Thuo, J.-W. Chen, and C.-N. Liu, "Failure investigation of a geosynthetic-reinforced soil slope subjected to rainfall," Geosynthetics International, vol. 26, no. 1, pp. 42-65, 2019.

[17] X. Zhang, L. Huang, Y. J. Hou, B. Wang, B. H. Xue, and M. S. Shi, "Study on the stability of the geogrids-reinforced earth slope under the coupling effect of rainfall and earthquake," Mathematical Problems in Engineering, vol. 2020, Article ID 5182537, 11 pages, 2020.

[18] J. J. Zhen, H. Yu, Z. S. Guo, and W. Z. Chao, "Numerical analysis of stability of widened embankment under rainfall conditions," Journal of Hunan University (Natural Science Edition), vol. 44, no. 7, pp. 150-155, 2017, in Chinese.

[19] P. Zhang, Y. F. Xu, and X. T. Wu, "Effects of water uptake by plant roots on slope stability," Journal of Yangtze River Scientific Research Institute, vol. 37, no. 9, pp. 120-125, 2020, in Chinese.

[20] M. S. Wu, C. Zhou, L. Wang, and C. M. Tan, "Numerical simulation of the influence of roots and fissures on hydraulic and mechanical characteristics of the soil," Rock and Soil Mechanics, vol. 40, no. s1, pp. 519-526, 2019, in Chinese.

[21] C. W. W. Ng, K. X. Woon, A. K. Leung, and L. M. Chu, "Experimental investigation of induced suction distribution in a grass-covered soil," Ecological Engineering, vol. 52, no. 2, pp. 219-223, 2013.

[22] H. X. Wang, Y. L. He, Z. F. Shang, C. P. Han, and Y. L. Wang, "Model test of the reinforcement of surface soil by plant roots under the influence of precipitation," Advances in Materials Science and Engineering, vol. 2018, Article ID 3625053, 12 pages, 2018.

[23] S. Y. Meng, Study on Unsaturated Infiltration Model and Ecological Reinforcement Mechanism of Slope under Rainfall Condition, China University of Geosciences, Beijing, China, 2019, in Chinese.

[24] W. W. N. Charles, "Atmosphere-plant-soil interactions: theories and mechanisms," Chinese Journal of Geotechnical Engineering, vol. 39, no. 1, pp. 1-47, 2017, in Chinese.

[25] X. R. Song, M. S. Huang, S. Q. He et al., "Erosion control treatment using geocell and wheat straw for slope protection,"
Advances in Civil Engineering, vol. 2021, Article ID 5553221, 12 pages, 2021.

[26] D. G. Fredlund, N. R. Morgenstern, and R. A. Widger, "The shear strength of unsaturated soils," Canadian Geotechnical Journal, vol. 15, no. 3, pp. 313-321, 1978.

[27] Y. R. Zheng, S. Y. Zhao, and L. Y. Zhang, "Slope stability analysis by strength reduction FEM," Chinese Engineering Science, vol. 4, no. 10, 2002, in Chinese. 